\title{
Indoor rock climbing: who gets injured?
}

\author{
D M Wright, T J Royle, T Marshall
}

\begin{abstract}
Objectives-To determine the frequency of overuse injury in indoor climbers, the common sites of such injury, and the factors that influence the probability that a climber will have sustained an overuse injury while climbing indoors.

Method-A semisupervised questionnaire was used to survey overuse injury in 295 spectators and competitors at the EntrePrises World Climbing Championships held in Birmingham 3-5 December 1999. Statistical analysis included simple cross tabulations, calculation of odds ratios, and multiple logistic regression to explore the effect of several factors simultaneously. Results-Some $44 \%$ of respondents had sustained an overuse injury, $19 \%$ at more than one site. The most common site of injury was the fingers. Univariate analysis showed that the probability of having sustained a climbing injury is higher in men $(p=0.009)$, those who have climbed for more than 10 years $(p=0.006)$, those who climb harder routes $(p<0.0005)$, and those who boulder or lead more than they top rope $(p<0.0005)$. The relation between lead grade and climbing injury is linear. Multivariate analysis removed the effect of sex as an independent predictor.

Conclusions-Many climbers sustain overuse injury. The most at risk are those with the most ability and dedication to climbing. Climbers should be aware of the risk factors that influence injury and be able to spot the signs and symptoms of injury once they occur.

(Br F Sports Med 2001;35:181-185)
\end{abstract}

Keywords: rock climbing; overuse injury; pulley tendon

University of

Birmingham School of

Medicine,

Birmingham, UK

D M Wright

T J Royle

Department of Public

Health and

Epidemiology,

University of

Birmingham

T Marshall

Correspondence to:

Mr Marshall, Department of

Public Health and

Epidemiology, The Public

Health Building, University

of Birmingham, Birmingham

B15 2TT, UK

t.marshall@bham.ac.uk

Accepted 29 January 2001 short intervals. However, such safety precautions and the secure comfortable indoor climbing environment created allow climbers to attempt routes beyond their ability and repeat strenuous manoeuvres on very small holds, potentially resulting in soft tissue injury. ${ }^{2}$

The predominant areas of injury are the elbow, wrist, forearm, and hand. ${ }^{5}$ Research has suggested that $75-90 \%$ of rock climbers can be expected to develop an upper limb overuse syndrome or injury. ${ }^{3-5}$ Many of the upper limb injuries (for example carpal tunnel syndrome, lateral epicondylitis, and interphalangeal joint effusion) sustained by rock climbers are also seen in other groups of sportsmen and women. However, there has been a gradual recognition by some health professionals that certain injuries are almost exclusive to rock climbers. The most common of these is "climber's finger", which is damage to the digital flexor tendon pulley systems, most commonly the A2 pulley tendon. ${ }^{26-9}$ This tendon is located on the volar aspect of the proximal phalanx and ensures that the flexor tendons do not bowstring when load is applied. ${ }^{10}$ Previous studies have reported damage to the A2 pulley tendon of the ring finger in $26 \%$ of the competition climbers surveyed, ${ }^{11}$ and that $69 \%$ of hand injuries occur in this area of the ring finger or middle finger. ${ }^{6}$

The users of climbing walls are a disparate group. It is extremely difficult to define the population to be studied and thus to obtain a representative or randomly selected sample. Previous studies have overcome this by presenting case reports ${ }^{12}$ or including only elite or competition rock climbers, who make up a very small proportion of the general climbing public. ${ }^{611}{ }^{13}$ Limb $^{14}$ investigated injury at British climbing walls, but data were collected from records of traumatic injury rather than from the climbers themselves. ${ }^{14}$ Thus there is still much scope to gather information on the relation between overuse injuries and the contributing factors in recreational users of indoor climbing walls - that is, the group that comprises the largest and fastest growing sector of climbing in Britain today.

Over the weekend of 3-5 December 1999, the British Mountaineering Council (BMC) hosted "Climb '99", at the National Indoor Arena in Birmingham. The focus of this event was the Entre-Prises World Climbing Championship, the highlight of the professional competition circuit. It was expected that over 5000 spectators would visit the event over the course of the weekend, probably the largest gathering of climbing enthusiasts ever seen in the United Kingdom. It was therefore decided to carry out an extensive survey of overuse injury sustained by competitors and spectators of all abilities.

Indoor climbing is generally subdivided into three different disciplines: bouldering, top roping, and leading. When bouldering, climbers attempt short routes without a rope, up to 
We are medical students at the University of Birmingham and are conducting a study into overuse (i.e. strain) injuries sustained at indoor climbing walls. We realise that this will exclude many other types of climbing injury including traumatic injuries and those incurred whilst climbing outside, but are focusing on this aspect because it has not been investigated in this way before.

We would be very grateful if you could help us compile data on this subject by completing the questionnaire below. All the information we receive will remain completely anonymous.

Please either fill in your answer or tick the relevant box/boxes, feel free to leave blank any questions which don't apply to you:

1. Sex: male $\square$ female $\square$

2. Age: ..... years

3. Age you started climbing: ..... years

4. Since this age (3), number of years in which you did no climbing: ..... years

5. Average number of trips you make to an indoor climbing wall each year: ..... trips

6. Please put the following in order according to amount of time you spend doing each whilst climbing at an indoor wall $(1=$ most, $3=$ least $)$ :

$$
\text { bouldering } \square \quad \text { top-roping } \square \quad \text { leading } \square
$$

7. What is your regular bouldering grade on an indoor wall?

$$
\text { upto } 4 \mathrm{c} \square \quad 5 \mathrm{a}-5 \mathrm{c} \square \quad 6 \mathrm{a}-6 \mathrm{c} \square \quad 7 \text { a and above } \square
$$

8. What is your regular lead grade on an indoor wall (English grade/French grade)?

$$
\text { upto HVS/F5+ } \square \quad \text { E1-E3/F6a-6c } \square \quad \text { E4-E5/F6c+-7b } \square \quad \text { E6/F7b+ and above }
$$

9. Have you ever sustained an overuse injury due to climbing at an indoor wall?

$$
\text { yes } \square \quad \text { no } \square \text { (if no please go to end) }
$$

10. In which parts of your body have you had an overuse injury? Please write in the number of times each part has been affected in this way.

$$
\text { fingers } \square \quad \text { wrist } \square \quad \text { forearm } \square \quad \text { elbow } \square \quad \text { shoulder } \square \quad \text { other (please specify) ..... }
$$

11. With respect to the most recent overuse injury you have sustained:

a) did this injury mean you had to stop climbing for a while?

b) if yes, how long was it before you started climbing again?

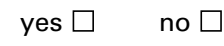

c) did you seek treatment or advice from any of the following? (tick all that apply)

Doctor $\square \quad$ Physiotherapist $\square \quad$ Chiropracter/Osteopath $\square$ Other (please specify) .....

d) did you receive any treatment? (tick all that apply) medical $\square \quad$ surgical $\square \quad$ manipulative $\square \quad$ other (please specify) ......

\author{
Thank you very much for taking the time to fill out this questionnaire. Enjoy the rest of Climb \\ '99! \\ James Royle and Deborah Wright (Medical Students, University of Birmingham) \\ Figure 1 Climbing injury questionnaire.
}

about $4 \mathrm{~m}$ above the ground. The floor area below is usually covered with crash mats allowing them to practise moves repeatedly that push the absolute limit of their physical and technical ability.

When top roping, the climber is tied to a rope that runs to the top of the wall through a screw gate karabiner and back to the belay partner at the base of the climb. As the rope is always above, the climber may rest without descending, may practise moves, and may be assisted by the belayer taking some of the climber's weight.
A lead climbing wall has lines of fixed bolts placed at intervals of about $1 \mathrm{~m}$. As the lead climber ascends the wall, he/she clips the rope through consecutive quick draws (two karabiners connected by a tape loop) so that, at any point, he/she can only fall a relatively short distance.

The technical difficulty of a climb is indicated by a grade. There are several grading systems but climbers are adept at conversion between them. The system used in this study for boulder problems uses letters and numbers in order of ascending difficulty: $4 c, 5 a, 5 b, 5 c$, 
Table 1 Risk factors for injury during indoor rock climbing: univariate results

\begin{tabular}{|c|c|c|c|c|c|c|c|}
\hline Factor & $\begin{array}{l}\text { Baseline } \\
\text { groups }\end{array}$ & Risk groups & $\begin{array}{l}\text { OR for } \\
\text { injury }\end{array}$ & Total $\chi^{2}(d f)$ & $p$ Value & $\chi^{2}$ for trend & $p$ Value \\
\hline Sex & $\mathrm{F}$ & M & 2.39 & 6.83 & $0.009^{\star}$ & & \\
\hline Preferred activity & Top roping & $\begin{array}{l}\text { Bouldering } \\
\text { Leading }\end{array}$ & $\begin{array}{l}2.42 \\
2.72\end{array}$ & $13.15(2)$ & $0.001^{\star}$ & 10.87 & $0.0009^{\star}$ \\
\hline Preferred activity & Top roping & Bouldering and leading & 2.54 & 12.98 & $<0.0005^{\star}$ & & \\
\hline Lead grade & Up to HVS & $\begin{array}{l}\text { E1-E3 } \\
\text { E4-E5 } \\
\text { E6+ }\end{array}$ & $\begin{array}{l}2.26 \\
4.3 \\
6.07\end{array}$ & $20.58(3)$ & $<0.0005^{\star}$ & 19.79 & $<0.0005^{\star}$ \\
\hline Bouldering & Up to $4 \mathrm{c}$ & $\begin{array}{l}5 a-5 c \\
6 a-6 c \\
7 a+\end{array}$ & $\begin{array}{l}2.46 \\
6.6 \\
5.87\end{array}$ & 24.76 (3) & $<0.0005^{\star}$ & 22.42 & $<0.0005^{\star}$ \\
\hline Age group & $<20$ & $\begin{array}{l}20-24 \\
25-34 \\
35+\end{array}$ & $\begin{array}{l}1.39 \\
1.36 \\
1.64\end{array}$ & $1.98(3)$ & 0.576 & 1.59 & 0.208 \\
\hline Years climbing & $0-4$ & $\begin{array}{l}5-9 \\
10+\end{array}$ & $\begin{array}{l}1.66 \\
2.66\end{array}$ & $10.31(2)$ & $0.006^{\star}$ & 10.28 & $0.0014^{\star}$ \\
\hline Visits per annum & up to 26 & $\begin{array}{l}27-52 \\
53-104 \\
>104\end{array}$ & $\begin{array}{l}1.62 \\
1.29 \\
3.56\end{array}$ & $10.28(3)$ & $0.016^{\star}$ & 6.14 & $0.0132^{\star}$ \\
\hline
\end{tabular}

6a, etc. Grading of top rope and lead climbing usually uses either the English or French system. Equivalent grades from each were used in the questionnaire, but to reduce confusion only English grades are used here.

\section{Methods}

During the three days of the event, we circulated 300 semisupervised self administered questionnaires to spectators and competitors who had finished their climbs. The only criteria for inclusion in the sample were presence at the event and a positive response to the initial question "have you ever climbed indoors?". Respondents recorded personal details, information on frequency of indoor climbing and climbing ability, and a history of previous injuries sustained while climbing indoors. The questionnaire included an introductory paragraph explaining clearly what was meant by "overuse injury", and stating that climbers were only to record overuse injuries (rather than traumatic injuries) sustained indoors. This was reiterated verbally. The questionnaire used predominantly closed questions and a "tick the box" format (fig 1).

Of the 300 questionnaires completed, five were discarded because of illegibility or incomplete or inappropriate responses, leaving 295 for analysis. Analytical methods used to explore the risk of injury included cross tabulations, calculation of odds ratios with their associated standard errors and confidence intervals, $\chi^{2}$ for trend (for ordered categorical factors), and unconditional multiple logistic regression to study the effect of risk factors in combination. The calculations were performed using EpiInfo release 6 , except for the logistic regression, for which Minitab was used.

Variables with more than two categories were ordered thus: preferred activity: top roping, bouldering, leading (representing increasing commitment); lead grade: up to HVS, E1-E3, E4-E5, E6+; bouldering grade: up to $4 \mathrm{c}$, 5a-5c, 6a-6c, 7a+; age: <20, 20-24, 25-34, 35+; years climbing: $0-4,5-9,10+$; visits per annum: up to $26,27-52,53-104,>104$. In the multiple regression, some of these categories had to be merged because of the small numbers in some cells.

\section{Results}

Of the 295 climbers surveyed, 131 (44\%) had sustained an overuse injury at some time; 57 $(19 \%)$ had suffered overuse injuries at more than one site, and many had repeatedly injured the same site, particularly the fingers. This was the most common injury site, strained by 94 $(32 \%)$ respondents, but other upper limb injuries were also described in substantial numbers. Six respondents had injured their knees and four their back, areas less characteristic of climbing injury.

Table 1 shows the results from the analysis of possible risk factors for injury. Of the factors explored, all except age have a statistically significant association with the probability that a climber will have sustained an overuse injury while climbing indoors.

We found trends in risk of injury in relation to: preferred activity (leading>bouldering >top roping); lead and bouldering grades (the harder, the greater the injury risk); number of years climbing (longer, more injury); and visits per year. The trend is most pronounced for lead grade. Where there is such a sequence, the change in odds ratio across categories is almost always linear, as reflected in both the $\chi^{2}$ for trend and the difference between that and the total $\chi^{2}$.

Table 2 gives the results from the multivariate analysis. Many different models were explored, using all the significant individual risk factors discussed above. There are many complex interrelationships between these factors. For example, there are relatively few women climbing at the very highest level of difficulty, and those climbers who prefer 
Table 2 Risk factors for injury during indoor rock climbing: multivariate results

\begin{tabular}{|c|c|c|c|c|c|c|c|}
\hline Factor & $\begin{array}{l}\text { Baseline } \\
\text { category }\end{array}$ & Risk groups & $\begin{array}{l}\text { Regression } \\
\text { coefficient (SE) }\end{array}$ & $z$ & $p$ Value & $\begin{array}{l}\text { Odds } \\
\text { ratio }\end{array}$ & $95 \% C I$ \\
\hline Preferred activity & Top roping & Bouldering and leading & $0.732(0.294)$ & 2.49 & 0.013 & 2.08 & 1.17 to 3.7 \\
\hline Lead grade & Up to HVS & $\begin{array}{l}\text { E1-E3 } \\
\text { E4+ }\end{array}$ & $\begin{array}{l}0.704(0.283) \\
1.24(0.415)\end{array}$ & $\begin{array}{l}2.49 \\
2.99\end{array}$ & $\begin{array}{l}0.013 \\
0.003\end{array}$ & $\begin{array}{l}2.02 \\
3.45\end{array}$ & $\begin{array}{l}1.16 \text { to } 3.52 \\
1.53 \text { to } 7.79\end{array}$ \\
\hline Years climbing & $<10$ & $10+$ & $0.851(0.356)$ & 2.39 & 0.017 & 2.34 & 1.17 to 4.7 \\
\hline
\end{tabular}

leading will also in general be undertaking the more difficult climbs. Thus many of these factors will be confounded with each other, and identifying the "best set" of such factors may be slightly arbitrary.

Nevertheless, two of the three factors emerging as significant in the final model are obvious. Number of years climbing is an obvious factor because we are looking at cumulative injury, as is lead grade. The unexpected factor included here is preferred activity (top roping $v$ bouldering and leading combined).

It is worth noting that the first model we tried included all the individual factors shown in table 1 except age and bouldering grade. This gave a $-2 \times \log$ likelihood of 166.8 with seven independent variables included. The final model, excluding non-significant variables and merging some categories of others, increased the log likelihood to 170.01 , but with three fewer variables included.

\section{Discussion}

The first point to consider about these findings is the representativeness of the subjects included in the study and thus the extent to which we can generalise the results beyond the immediate sample. This is a difficult issue: there is no population list of climbers that could be used as a sampling frame, still less one consisting only of those who climb indoors. It is impossible to say therefore that the sample obtained is representative of a population of indoor climbers. At the same time, it is difficult to suggest any other method whereby a large number of indoor climbers, covering a wide range of ability and experience, could be questioned in so short a time.

As our sample is not random, it is inappropriate to make much of overall injury frequency, because the proportions of the sample, by sex, lead grade, etc, may be quite unrepresentative of whatever we might construe the "population" of indoor climbers to be. However, this criticism does not apply, or applies only to a far lesser extent, if we consider the risks of injury in different subcategories of our sample. It is not unreasonable to suggest that the relative risks of injury for men (compared with women) or those climbing at the hardest level (compared with those climbing at lower grades) are probably quite close to the "real" risks. This remains the case even though our sample may not contain "true" population proportions of male climbers or "true" proportions of those who climb at the highest grade of difficulty. The one extra factor for which we cannot properly account is interaction effects between, for example, sex and lead grade, simply because the data set is not large enough.
The response variable "have you ever sustained an overuse injury?" did not allow us to calculate either incidence or prevalence. In the context of how and where the questionnaire was delivered it was impracticable to ask about how many injuries each respondent had sustained in the course of the indoor climbing career (problems with recall bias are obvious), or to distinguish between recurrent and new injuries. Had we investigated the incidence of injury over a shorter time frame-for example, the last 12 months - it is likely that the numbers would have been so low that it would not be possible to explore risk factors, the aim of this study. A proper investigation of incidence would have required a more extensive study than was possible in the time available.

Conventionally, prevalence is used to reflect the burden of chronic disease within a population. Overuse injuries are acute, therefore only a small proportion of those respondents who have ever been injured would have an injury at the time of questioning, so producing the same problem with sample size as measuring incidence. Furthermore, many of the respondents in the top categories of ability were competing at the event and are unlikely to have been injured at the time.

In considering the multivariate findings, the following points deserve comment. Sex disappears as an independent predictor, presumably because of its relation to lead grade. That lead grade and number of years climbing remain as independent predictors is in some respects fairly obvious, but it is interesting that visits per annum is not an independent predictor. This must be because of its relation to lead grade: people become capable of climbing hard, both because of intrinsic ability and because they train frequently. However, frequent visits to a wall would not be so likely to occasion an overuse injury if the climber is climbing at a relatively low level, because the physical strain involved is necessarily less than for those climbing at a high level.

The factor we had not expected to appear in the final model is "preferred activity". Independently of the ability of the climber, bouldering and leading are more likely to result in injury than top roping. We suggest that these factors represent increasing commitment on the part of the climber and thus a potential for greater strain. It is, nevertheless, a surprise that both lead grade and preferred activity feature in the final model.

It may be asked whether any recommendations can be made on the basis of these findings that would reduce the risk of injury. In practice, the answer must be a firm "no". Advising people that they should prefer a less committing 
activity or only climb easier routes is pointless, as is suggesting that climbers should retire after 10 years. Perhaps the best that can be offered is for the results of this and other studies to be made widely available in the specialist press, so that climbers can be informed about how common these injuries are, of their risk factors and, from other studies, of the signs and symptoms of overuse injury.

We thank the BMC for help and cooperation with this study in allowing us access to the Climb ' 99 event.

$1 \mathrm{http}: / /$ www.thebmc.com

2 Humphries D. Diagnosis, management, and prevention of climbing injuries. Medscape Orthopaedics and Sports Mediclime 1998;2.

3 Rooks MD, Johnston RB, Ensor CD, et al. Injury patterns in recreational rock climbers. Am F Sports Med 1995;25:6834 Shea KG, Shea BA, Meals RA. Manual demands and con-
sequences of rock climbing. 7 Hand Surg [Am] 1992;17: sequen $200-5$.

5 Holtzhausen L-M, Noakes TD. Elbow, forearm, wrist and hand injuries among sport rock climbers. Clin f Sport Med 1996;6:196-203.

6 Bollen SR. Soft tissue injury in extreme rock climbers. $\mathrm{Br} \mathcal{F}$ Sports Med 1988;22:145-7.

7 Preston D. Rock climbing reaching new heights. http:// www.hughston.com/hha/a.climb.htm

8 Rooks MD. Rock climbing injuries. Sport Med 1997;23;26170 .

9 Bollen SR. Injury to the A2 pulley in rock climbers. 7 Hand Surg $[\mathrm{Br}]$ 1990;15:268-70.

10 Jebson PJL, Steyers CM. Hand injuries in rock climbing: reaching the right treatment. Physician and Sportsmedicine 1997;25:54-63.

11 Bollen SR, Gunson CK. Hand injuries in competition climbers. Br F Sports Med 1990;24:16-18.

12 Bannister P, Foster P. Upper limb injuries associated with rock climbing. Br $\mathcal{F}$ Sports Med 1986;20:55.

13 Bollen SR. Upper limb injuries in elite rock climbers. $f R$ Coll Surg Edinb 1990;35(suppl):18-20.

14 Limb D. Injuries on British climbing walls. Br f Sports Med 1995;29:168-70.

\section{Take home message}

Many climbers sustain overuse injuries, particularly to their fingers, while climbing indoors. Climbers who climb at higher grades, or who boulder and lead climb in preference to top roping, place themselves at greater risk.

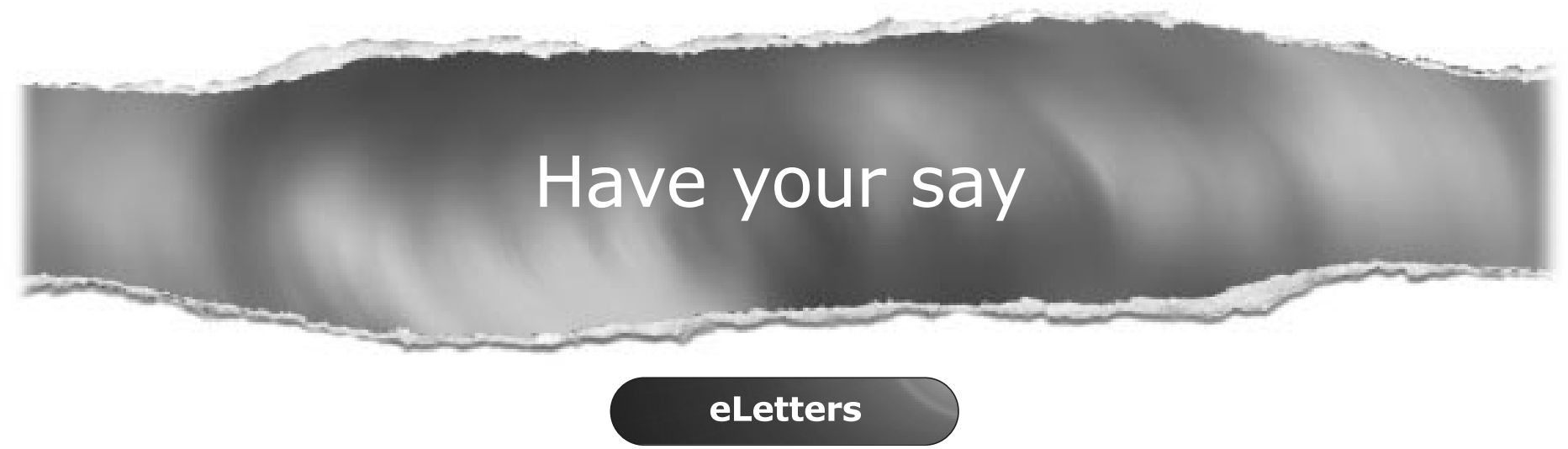

If you wish to comment on any article published in the British Journal of Sports Medicine you can send an eLetter using the eLetters link at the beginning of each article. Your response will be posted on British Journal of Sports Medicine online within a few days of receipt (subject to editorial screening).

www.bjsportmed.com 